\title{
Forking Paths in New Media Art Practices: Investigating Remix
}

\section{XTINE BURROUGH}

Professor and Area Head, Design + Creative Practice, School of Art, Technology, and Emerging Communication, The University of Texas at Dallas

\section{OWEN GALLAGHER}

Assistant Professor and Programme Manager, Web Media Department, School of Creative Media, Bahrain Polytechnic

\section{EDUARDO NAVAS}

Associate Research Professor, Head of Critical Studies; Art, Digital Arts \& Media Design, The Pennsylvania State University

This special issue of Media- $N$ on contemporary approaches to remix was inspired by Jorge Luis Borges's short story, "The Garden of Forking Paths," a recurring point of reference in the development of media culture. ${ }^{1}$ Prior to terms such as new media, digital art, media art, and remix, Borges's narrative exploration of bifurcation as a means of reflecting on the possibility of multiple simultaneous realities with no clear beginning or end has offered a literary and philosophical model for creative uses of emerging technology throughout the twentieth century. The essays included in this special issue provide a glimpse into the relation of Borgesian multiplicity and remix as an interdisciplinary methodology.

The issue brings forth the sprawling role remix continues to play in cultural production beyond the arts. Contributions to this issue, in the forms of essays, artists' case studies, and experimental writing, provide different points of entry into remix in terms of digital art practice, which in turn informs a wider interdisciplinary spectrum among the arts, humanities, and social sciences. One pivotal question that each contribution takes up is what type of criticality may be at play in contemporary digital art and culture - particularly in the area of remix itself, now that the concept is not only commonly understood in the mainstream, but is also considered a subject of research. From an ethical point of view, remix is a critical act that frequently involves the reuse of creative works without the original author's sanction, thereby implicitly critiquing the ethical basis of copyright law in its present form. As a rhetorical strategy, remix has the potential for even greater criticality: it can be used as a highly effective weapon against a multitude of propagandistic targets. Often in the form of critical or political remix, the remixer uses the power and weight of a target against itself, maneuvering and manipulating media as a semiotic form of jiu-jitsu. Like Borges's short story, this act forces audiences to consider multiple, forking interpretations of traditionally monolithic mainstream media messages, thus inspiring greater criticality among viewers and users, as well as among artists and producers. 
Remix studies is a field of research that often produces unexpected connections between hard and soft disciplines that have traditionally maintained intellectual distance from one another, such as the humanities and the sciences. Like the digital humanities, remix studies frequently bridges gaps between formerly incompatible areas through the implementation of digital technologies, leading to fruitful multi-disciplinary collaborations across various areas of research and production. Over the last decade, the rise of remix as a cultural activity has been explored in a number of international conferences with the aim of evaluating its importance beyond music - thus crossing over to various fields in the arts, humanities, and social sciences. Remix as an interdisciplinary subject of research has found its way through many forking paths to appear across different peer-reviewed journals; yet it has seldom received attention as a dedicated topic for journal issues. For this reason, the papers included in this Media- $N$ special issue on remix share a focus on its diverging influence on criticality in digital media. The special issue reflects on, and, in its own way, is an indirect update on subjects previously discussed in the Media- $N$ issue "Found, Sampled, Stolen: Strategies of Appropriation in New Media" (8, no. 2 [2012]). That issue focused on appropriation and fair use as, or on, equal grounds with remix. The current issue enables readers to reflect on the role of remix across disciplines, entangled in critical arguments that touch on how individuals and collaborative groups relate to creativity now that the practice of remixing is commonly acknowledged across various areas of culture. For this special issue, we posit that remix itself bifurcates into multiple possibilities for communication and expression across our increasingly networked society.

More specifically to remix, we found Borges's concept of forking paths to be a fitting metaphor for this special issue of Media- $N$ because the bifurcating realities explored in his short story are considered an inspiring, and arguably, a founding text of what digital art is and could be. The short story, indeed, has been cemented as an important reference in digital media art and culture, as it continues to inspire possibilities for interactive storytelling. ${ }^{2}$ The New Media Reader, edited in 2003 by Noah Wardrip-Fruin and Nick Montfort, opens with Borges's story, establishing creativity as central and foundational to the ongoing development of computing both in what we call digital art today and in our networked global culture. ${ }^{3}$

In the years since the previous Media- $N$ special issue in 2012, remix has evolved to become both a subject of research and practice beyond the arts; ${ }^{4}$ therefore, in this issue we include interdisciplinary contributions that come from diverse and unexpected paths, relevant across different fields of research and practice. These contributions enable us to reflect on the broad effects of remix as an interdisciplinary cultural activity, and to investigate how this broadening reshapes remix practice in the visual arts, particularly digital media.

\section{CULTURAL CONTEXT: FORKING PATHS ACROSS DISCIPLINES}

Borges's short story functions as a meta-narrative that presents the multiplicity of experience across the universe as an "...infinite series of times, a growing dizzying web of divergent, convergent, and parallel times."

The story's multilayered complexity, which includes world war conflict, racial and ethnic tension, and the complexities of acknowledging one's own heritage, presents the main character, Yu Tsun, as a conflicted man who murders Stephen Albert, the keeper of the garden of forking paths. Tsun realizes that his narrative, which we experience as readers, is but one possible path his destiny could 
take. In this sense Borges's story provides a template for the type of possibilities that our own reality took and continues to take as we navigate metaphorically in the stories we tell with the development and use of communication technologies that shape the $21^{\text {st }}$ century.

Thus, Borges's story preceded and continues to resonate with the growing interest in what Theodor Holm ("Ted") Nelson termed hypertext ${ }^{6}$ during the early days of virtual networks, leading to the burgeoning contemporary field of electronic literature. ${ }^{7}$ The concept of multiple realities found in Borges's short stories are versions, not so different from the practice of remixing pre-existing sounds in Dub music. In popular culture, this tendency is considered part of transmedia storytelling and is most obvious in major franchises, such as comic book multi-verses turned films, video games, and TV shows. ${ }^{8}$ Borges's approach to writing also preceded the non-linear philosophy of Gilles Deleuze and Felix Guatarri (D \& G) in their seminal publications Anti-Oedipus and $A$ Thousand Plateaus. (D \& G are admittedly critical of Borges's approach to multiplicities when they developed their own theory of the rhizome. ${ }^{9}$ ) Borges's work has also influenced Jean Baudrillard, who opens his book Simulacra and Simulation with a discussion of Borges's one paragraph fiction "On Exactitude in Science." 10 In effect, the premises in Borges's work have contributed to the rise of a field of philosophy today known as non-linear ontology. ${ }^{11}$

Borges alluded to being a kind of remixer in his own right. In the preface to his book of short stories, A Universal History of Iniquity, he wrote about his decision to reprint the short stories comprising that book as they were first published: "They are the irresponsible sport of a shy sort of man who could not bring himself to write short stories, and so amused himself by changing and distorting (sometimes without aesthetic justification) the stories of other men."12 As a writer sampling others' stories, Borges reveals the possibility for multiplicity, of versioning as a form of becoming. ${ }^{13}$

Borges was in effect a meta-writer, one who is often associated with the literary novel; however, he never actually published a novel himself. As Wardrip-Fruin and Montfort note, "He [Borges] found it sufficient to encode ideas rich enough for treatment in a novel in a format which was smaller than the typical short story, a format called a "fiction." ${ }^{14}$ Borges, in this sense, exposes multiple layers of meta-production that have become the driving forces behind our media culture. In short, his approach is one of remix. For this reason, we decided to reference his short story as a point of entry to revisit how remix has evolved in multiple forking paths of its own. The contributions that form part of this special issue of Media- $N$ present a small sample of the ongoing research and creative production fueled by remix as a practice of bifurcation.

\section{CONTRIBUTIONS}

The essays in this issue vary in their emphasis, while directly relating to the role of remix in digital art and creativity. The range of focus includes reflections on the relation of remix and creativity in artificial intelligence, biology, and language; others reflect on the political environment in the United States since 2016, which in turn affects the political climate around the world. The authors engage with specific questions: What type of role does remix play in education? How do practitioners utilize remix as a strategy-for instance, for disruption, change, or communication? What are the implications for political/media credibility and accountability in an age when advanced technologies and remix creativity can be used to significantly alter political speech and 
journalistic media broadcasts for artistic purposes? How does remix function in relation to fake news and/or deep fakes? What role does remix play in the ongoing emergence of artificial intelligence and machine learning? The contributors' academic backgrounds are diverse, bringing together different fields of practice, including computer science, music, art, and the social sciences. All of the contributions, including those that fit a straightforward format of the academic essay, share an intimate relation to hands-on practice. The issue begins with essays in a scholarly format, followed by reflection essays about creative projects. It ends with a section specifically dedicated to experimental writing, which brings together theory and practice in the form of remixed works.

Scott Church's essay takes on Borges's short story about Funes, who possesses a perfect memory, in order to reflect on the role DJ crate diggers play in current times as exemplar figures of the act of curating. Church argues that with the rise of automation and big data, the ability to select and curate material from vast amounts of information is emerging as a creative and critical feature in the human endeavor for creative practice. He argues that unlike Funes, who saw his perfect memory as a curse, people who have a strong sense of selectivity and the ability to engage with large amounts of information can be considered "exemplars of how to filter and make meaning from information overabundance." He provides two case studies to support his argument: remixed albums by DJ Shadow and J Dilla.

Lucy HG Solomon and Cesar Baio, as the art collective Cesar \& Lois, contribute a critical reflection on their collaboration Degenerative Cultures. This project explores different forms of logic that are redefining the Anthropocene. Cesar \& Lois mashes up biology and artificial intelligence to produce a series of texts that, through deterioration or destruction and based on natural processes steered by an AI program, opens potentials for creativity in which the author is repositioned as a scientific researcher who poses questions that cannot be answered quantifiably. The project encourages viewers to interrogate their relation to natural changes, especially as artificial intelligence is implemented to disrupt philosophical works by means of organic growth.

In Liat Berdugo's essay "Remix and Reproduction in the Post-Internet Age: A Contemporary Art + Design Pedagogy," the author discusses the relation of remix to visuality. She argues that artists and designers remix visuality based on principles closely linked to music. She also states that "remix practices reconfigure notions of originality and authenticity within the disciplines of art and design," and sets out to discuss how she explores the possibilities of remix and visuality in the classroom. Her essay includes her analysis of work produced by design students.

Tess Baxter's contribution focuses on her creative output of machinima videos based on "found collaboration," which in her view takes place when "people make work available for reuse without knowing who might use it, or for what purpose." ${ }^{15}$ Her essay is a reflection on how remix plays a role in the ongoing development of machinima based on Second Life through "digital exceptionalism."

Andrew Demirjian discusses his practice as a sound artist in terms of remix. His work has a clear political focus; he reflects on flags and national anthems, including lyrics and music from 195 countries. His interdisciplinary work asks the viewer to reconsider assumptions about music and visual language that appeal to human emotions. He argues that "remix strategies can be used to unravel our concepts of nations, which traditionally magnify differences between countries and 
overemphasize a false sense of uniqueness," and he provides a sound argument for everyone to become engaged in self-reflection about the politics of national identity in times of great cultural division around the world.

Diran Lyons reflects on a series of digital collages he has produced in recent years. Lyons is a longtime producer of critical remix videos with a clear political focus critiquing the discourses of both left and right. He discusses his method of producing collages according to "additive, subtractive, and substitutive remix strategies to integrate Gothic, Renaissance, and Baroque paintings with visages of Donald Trump and his associates." His work is focused on demonstrating how remix can be a powerful tool for critical reflection based on the strategy of disruption, one that is elemental in the genre of critical remix.

Alina Nazmeeva discusses remix in the social space. She mashes together architectural and urban discourse in order to make sense of the ongoing hybridity among physical and informational experience. She notes that remix is often understood in terms of music and media, while architecture can be analyzed in terms of a shared social experience often closely connected to our physicality. She proposes that "remix has become the dominant model of spatial production in the contemporary world," leading her to ask "what are the implications of [remix] for the social space and publics?"

In "Proclamations and Paraphernalia: \#Bellwether, Editor's Notes, and the Art of Remixing the Political Document" Roopa Vasudevan provides a critical overview of two of her works, \#Bellwhether and Editor's Notes. The former focuses on the elections of 2016, particularly on what took place in Ohio; the latter is a remix of the US Constitution using Tweets by Donald Trump, as well as his executive orders and memoranda. Vasudevan's goal for both projects is to implement remix strategies that point to "a way of imagining a more nuanced approach to current political analysis and meaning-making." Her pieces and her own critical reflection on her implementation of appropriation as a means to remix exposes the very structure utilized by propaganda, often repurposed as a tool of otherization under "fake news."

Desiree D'Alessandro discusses how remix plays an important role in her art practice as well as in her life. She takes Borges's short story of "The Garden of Forking Paths" as a point of entry to discuss her relation to the philosophy of Gilles Deleuze. Her essay reflects on the possibilities of critical remix as a creative practice that moves beyond its immediate community to become a means for critical reflection on various cultural levels, including the simple moments of life itself, as she explains, "the labyrinth of everyday existence."

Rebecca Modrak shares a brief reflection to introduce her work Re Made, an online project that exposes the absurd direction that online brand messaging can take. Her website mimics the Best Made website in a clear act of rhetorical and aesthetic appropriation. Her online project is meant to function as a critical space in the spirit of parody, touching upon the thin line of critical reflection through absurdity and straightforward propaganda currently debated, projected, and dismissed as "fake news."

Michael Szpakowski contributes a critical reflection - in the form of a remix of a critical reviewof his project 12 Remixes. Szpakowski sampled his review by Edward Picot to develop a critical 
text which blurs the line between criticism and self-reflection. The result is a work that functions as a hall of mirrors, in which it becomes difficult to know what is being remixed, and where the voice of the remixer takes over to push the text beyond mere derivativity.

MALK, a collaboration between Mark Amerika, Laura Hyunjhee Kim, and Brad Gallagher, contributes a brief critical reflection on "The Robot Does Not Exist: Remixing Psychic Automatism and Artificial Creative Intelligence," a transmedia experimental piece which explores the possibilities of artificial intelligence in the creative process. They refer to their ongoing project as an "Imaginary Digital Media Object" (IDMO), which they consider an intervention in academic production. Their aim is to make the most of an unstable loop in which "the text becomes image and the image becomes text, a mutual dematerialization and rematerialization that mutates in a cycle of transformation." Following their introduction to the work, readers can follow the link to MALK's IDMO track.

As is evident, the essays included in this special issue are written by individuals who have a very close relationship to remix as a form of hands-on production, and who discuss pressing contemporary questions such as artificial intelligence, human beings' relationship to nature and the environment, remix in social spaces from architecture to the classroom, as well as ongoing political conflicts not just in the US but around the world. These authors have contributed texts that emerge from a moment marked by cultural, ecological, and political impasses, in which remix has proven to play a role in both critical reflection and viral dissemination of misinformation. These essays offer a glimpse into crises that cross boundaries of the natural environment, political communication in virtual spaces, and the production of social spaces. While we continue to work creatively during a global public health crisis, we offer this special issue to suggest that remix is a praxis for critical reflection, creative activism, and for making meaning during complicated times. The question that lingers, which in a way is part of remix's own loop within cultural production, is What is the future of remix as a creative paradigm? The answer, as the essays in this special issue may demonstrate, is not a simple one; there may well be no answer; or if there is one, it may be that we experience remix as it continues to change in the ongoing process of versioning, of becoming in multiplicities, what $\mathrm{Yu}$ Tsun experienced in the garden: multiforms "in other dimensions in time. $" 16$

\section{ENDNOTES}

1. Jorge Luis Borges, "The Garden of Forking Paths," Collected Fictions, trans. Andrew Hurley (New York: Penguin Classics, 1998), 119-128.

2. Borges's pervasive literary and cultural influence persists. See Noam Cohen, "Borges and the Foreseeable Future," The New York Times: January 2008, accessed November 11, 2020, https://www.nytimes.com/2008/01/06/books/06cohenintro.html; Rocinante; "Jorge Luís Borges, Infinity, and the Internet," The Anvil: May 23, 2010, accessed November 11, 2020; Jonathan Basile, "Putting Borges' Infinite Library On the Internet," Electric Lit: June 21, 2016, accessed November 11, 2020, https:/electricliterature.com/putting-borges-infinite-library-on-the-internet/

3. Noah Wardrip-Fruin and Nick Montfort, eds., "Introduction: The Garden of Forking Paths," The New Media Reader (Cambridge, MA: MIT Press, 2003), 29-34. 
4. See The Routledge Companion to Remix Studies (2015), Keywords in Remix Studies (2018) and The Routledge Handbook of Remix Studies and Digital Humanities (2021) for further detailed discussion on this.

5. Borges, 127.

6. Ted Nelson, "A File Structure for the Complex, the Changing, and the Indeterminate," Association for Computing Machinery: Proc. 20th National Conference, (1965), 84-100.

7. See the Electronic Literature Organization, https://eliterature.org/.

8. Transmedia storytelling occurs when a narrative takes place across multiple media. For example, while watching the latest Spider-Man movie, viewers might receive a GPS-targeted text message to their phone, an update from the fictional "Daily Bugle" newspaper, providing a code to log on to the MCU website, where they can access DLC for the official PS4 Spider-Man video game. Adaptation is a related concept, whereby a narrative may originate in one media form, such as a comic book, and be subsequently converted to a different media form, such as a film franchise, like The Avengers, Spider-Man, Batman, Star Wars, The Matrix universe, and so forth.

9. Deleuze and Guatarri are critical of Borges's book History of Universal Infamy, as well as of his Book of Imaginary Beings. See, Gilles Deleuze and Felix Guatarri, A Thousand Plateaus: Capitalism and Schizophrenia, trans. Brian Massumi (Minneapolis: University of Minnesota Press, 1987). 125, 241.

10. Jean Baudrillard, "The Precession of Simulacra," Simulacra and Simulation, trans. Sheila Faria Glaser (Ann Arbor: The University of Michigan Press, 1994), 1-3. Borges, "On Exactitude in Science," 325.

11. See Manuel de Landa, A Thousand Years of Nonlinear History (New York: Zone Books, 1997).

12. Borges, Collected Fictions, 4.

13. This is a Deleuzean concept discussed in many of Deleuze's books, including those previously mentioned that were published in collaboration with Felix Guatarri.

14. Wardrip-Fruin and Montfort, 29.

15. All quotes are derived from the individual article's abstract.

16. Borges, 127.

\section{REFERENCES}

Baudrillard, Jean. "The Precession of Simulacra.” Simulacra and Simulation. Translated by Sheila Faria Glaser. Ann Arbor: The University of Michigan Press, 1994, 1-42.

Borges, Jorge Luis. "The Garden of Forking Paths." Collected Fictions. Translated by Andrew Hurley. New York: Penguin Classics, 1998. 119-28.

. "On Exactitude in Science." Collected Fictions. Translated by Andrew Hurley. New York: Penguin Classics, 1998. 325.

de Landa, Manuel. A Thousand Years of Nonlinear History. New York: Zone Books, 1997. 
Deleuze, Gilles, and Felix Guattari. Anti-Oedipus: Capitalism and Schizophrenia. Translated by Robert Hurley. Minneapolis: University of Minnesota Press, 1983.

- A Thousand Plateaus: Capitalism and Schizophrenia. Translated by Brian Massumi. Minneapolis and London: University of Minnesota Press, 1987.

Navas, Eduardo, Owen Gallagher, and xtine burrough. The Routledge Companion to Remix Studies. New York: Routledge, 2015.

—. Keywords in Remix Studies. New York: Routledge, 2018.

- The Routledge Handbook of Remix Studies and Digital Humanities. New York: Routledge, 2021.

Nelson, Theodor Holm. "A File Structure for the Complex, the Changing, and the Indeterminate." Association for Computing Machinery: Proc. 20 $0^{\text {th }}$ National Conference, 1965. 84-100.

Wardrip-Fruin, Noah and Nick Montfort, eds. "Introduction: The Garden of Forking Paths," The New Media Reader. Cambridge, Massachusetts: MIT Press, 2003. 29-34. 